\title{
GERMINAÇÃO DE SEMENTES DE MELÃO OSMOTICAMENTE CONDICIONADAS DURANTE O ARMAZENAMENTO ${ }^{1}$
}

\author{
WARLEY MARCOS NASCIMENTO²
}

\begin{abstract}
RESUMO - O condicionamento osmótico das sementes de melão pode amenizar o efeito inibitório das baixas temperaturas, melhorando, assim, a germinação e a emergência das plântulas no campo. O objetivo desse trabalho foi avaliar a viabilidade das sementes de melão condicionadas e não condicionadas durante o armazenamento. Sementes de melão foram condicionadas por nove dias, a $25^{\circ} \mathrm{C}$, em solução aerada de $\mathrm{KNO}_{3}(0,35 \mathrm{M})$. As sementes condicionadas ou não foram acondicionadas em envelopes aluminizados e armazenadas por $0,6,12,18$ e 24 meses em condições ambientais de laboratório. Sementes condicionadas apresentaram uma maior deterioração durante o armazenamento, sendo que, após 24 meses, apenas 30\% germinaram, comparado com $78 \%$ nas sementes não condicionadas. Estudos devem ser enfatizados visando, simultaneamente, alcançar um efeito positivo do condicionamento e minimizar os efeitos deletérios durante o armazenamento.

Termos para indexação: Cucumis melo, condicionamento, estabelecimento das plântulas, deterioração.
\end{abstract}

\section{GERMINATION OF PRIMED MUSKMELON SEEDS DURING STORAGE}

\begin{abstract}
Seed priming may overcome the inhibitory effect of low temperatures and increase germination and seedling establishment in the field. The objective of this study was to compare seed viability between primed and unprimed seeds during storage. Muskmelon seeds were primed in $\mathrm{KNO}_{3}(0.35 \mathrm{M})$ aerated solution for nine days at $25^{\circ} \mathrm{C}$. Primed and unprimed seeds were placed in aluminum bags and stored for 0, 6, 12, 18 e 24 months in laboratory conditions. Primed seeds had higher deterioration during storage. After 24 months, primed seeds germinated $30 \%$, whereas unprimed seeds germinated $78 \%$. Further studies of seed priming might allow improvements in this process to achieve simultaneously maximum enhancement effect of seed priming and minimize the deleterious effects during storage.

Index terms: Cucumis melo, osmotic conditioning, stand establishment, seed deterioration.
\end{abstract}

\section{INTRODUÇÃO}

O condicionamento osmótico consiste em embeber as sementes em uma solução osmótica por um determinado período de tempo e fazer, em seguida, uma secagem das mesmas para o grau original de umidade (Nascimento, 1998). Os efeitos benéficos do condicionamento osmótico na germinação de sementes de melão têm sido previamente relatados (Bradford, 1985; Nerson \& Govers, 1986; Bradford et al., 1988; Passam et al., 1989; Welbaum \& Bradford, 1991;

\footnotetext{
${ }^{1}$ Aceito para publicação em 30.12.2001.

${ }^{2}$ Eng $^{\circ}$ Agr $^{\circ}$, PhD., Pesquisador Embrapa Hortaliças; CX. Postal 218, 70359970, Brasília-DF; e-mail: wmn@cnph.embrapa.br
}

Dhillon, 1995; Oluoch \& Welbaum, 1996; Yeoung et al., 1996 e Nascimento \& West, 1998 e 1999).

Um aspecto importante na manutenção da qualidade das sementes é a redução da deterioração durante o armazenamento (Harrington, 1972). Tem sido relatado que o condicionamento osmótico reduz a qualidade fisiológica das sementes de várias espécies durante o armazenamento (Alvarado \& Bradford, 1988; Argerich et al., 1989; Carptenter \& Boucher, 1991; Maude et al., 1994; Odell \& Cantliffe, 1986 e Nascimento \& Cantliffe, 1998) incluindo melão (Oluoch \& Welbaum, 1996). Além disso, condições inadequadas de armazenamento podem acelerar a deterioração das sementes condicionadas (Georghiou et al., 1987 e Sanfield et al., 1990). Em outros estudos, o condicionamento osmótico não afetou 
a longevidade das sementes de cebola (Dearman et al., 1986) e cenoura (Dearman et al., 1987)

O objetivo do presente trabalho foi comparar a germinação das sementes de melão condicionadas e não condicionadas durante 24 meses de armazenamento.

\section{MATERIAL E MÉTODOS}

O trabalho foi realizado no Laboratório de Sementes do Departamento de Agronomia da Universidade da Flórida, Gainesville, EUA, no período de 1996 a 1998. Um lote de sementes de melão cv. Top Net SR (Harris Moran Seed Co.) foram condicionadas por nove dias, no escuro, a $25^{\circ} \mathrm{C}$, em solução aerada de $\mathrm{KNO}_{3}(0,35 \mathrm{M})$. A aeração foi provida por uma bomba de aquário. As sementes foram colocadas em frascos de $250 \mathrm{ml}$ com $10 \mathrm{ml}$ de solução por grama de sementes e a solução osmótica trocada a cada três dias. Ao final do período, as sementes foram lavadas em água corrente, por dois minutos, e em seguida, colocadas para secar em condições de ambiente de laboratório $\left(24-27^{\circ} \mathrm{C}\right.$ e $50 \%$ de UR) por quatro dias. Sementes condicionadas ou não foram acondicionadas em envelopes aluminizados ("pouches") e armazenadas por $0,6,12,18$ e 24 meses em condições de ambiente de laboratório $\left(15-30^{\circ} \mathrm{C}\right.$ e $30-80 \%$ de UR). Quatro repetições de 50 sementes foram colocadas para germinar em placas de petri contendo duas folhas de papel de germinação, umedecidas com $10 \mathrm{ml}$ de água destilada e incubadas em germinadores a $25^{\circ} \mathrm{C}$, com luz fluorescente $\left(\sim 26 \mu \mathrm{mol} . \mathrm{m}^{-2} \cdot \mathrm{s}^{-1}\right)$ por oito dias. Para o teste de emergência das plântulas, quatro repetições de 50 sementes foram semeadas em bandejas de poliestireno (200 células), contendo um substrato comercial (Metro-Mix 350, Scotts-Sierra Horticultural Products Co., Marysville, Ohio). As bandejas foram colocadas em casa de vegetação (20-32 ${ }^{\circ} \mathrm{C}$ e $65-85 \%$ de UR), e irrigadas manualmente quando necessário. A emergência das plântulas foi avaliada aos 14 dias após a semeadura.

\section{RESULTADOS E DISCUSSÃO}

O grau de umidade original das sementes foi de $7,0 \%$. No final do período de condicionamento (nove dias), a umidade das sementes subiu para 50,4\%. Não foi observada protrusão da radícula durante o condicionamento osmó- tico. A umidade das sementes após quatro dias de secagem em ambiente de laboratório foi de $6,7 \%$. Assim, sementes condicionadas e não condicionadas foram armazenadas com 6,7 e $7,0 \%$ de umidade, respectivamente.

Utilizando a mesma cultivar de melão, Nascimento \& West (1999) observaram germinação maior e mais rápida a $17^{\circ} \mathrm{C}$ nas sementes condicionadas, confirmando que o condicionamento osmótico, em melão, pode ser altamente benéfico, principalmente nas condições adversas de germinação a baixas temperaturas. Já em condições ótimas, a porcentagem de germinação das sementes condicionadas e não condicionadas foi a mesma. Neste trabalho, a germinação inicial das sementes foi 90 e $94 \%$ para as sementes condicionadas e não condicionadas, respectivamente (Figura 1). A emergência das plântulas, em condições de casa de vegetação, foi de 88 e $90 \%$ para as sementes condicionadas e não condicionadas, respectivamente (Figura 1). Entretanto, com o decorrer do período de armazenamento, as sementes condicionadas apresentaram maior deterioração, sendo que após 24 meses, apenas $30 \%$ germinaram, comparado com $78 \%$ das sementes não condicionadas (Figura 1). A emergência das plântulas oriunda de sementes condicionadas, após esse período de armazenamento, foi de apenas $24 \%$, enquanto que as sementes não condicionadas emergiram 64\% (Figura 1). Em outro trabalho com melão cv. Top Mark, Oluoch \& Welbaum (1996) verificaram também que o condicionamento osmótico foi deletério para a longevidade das sementes. Embora a técnica

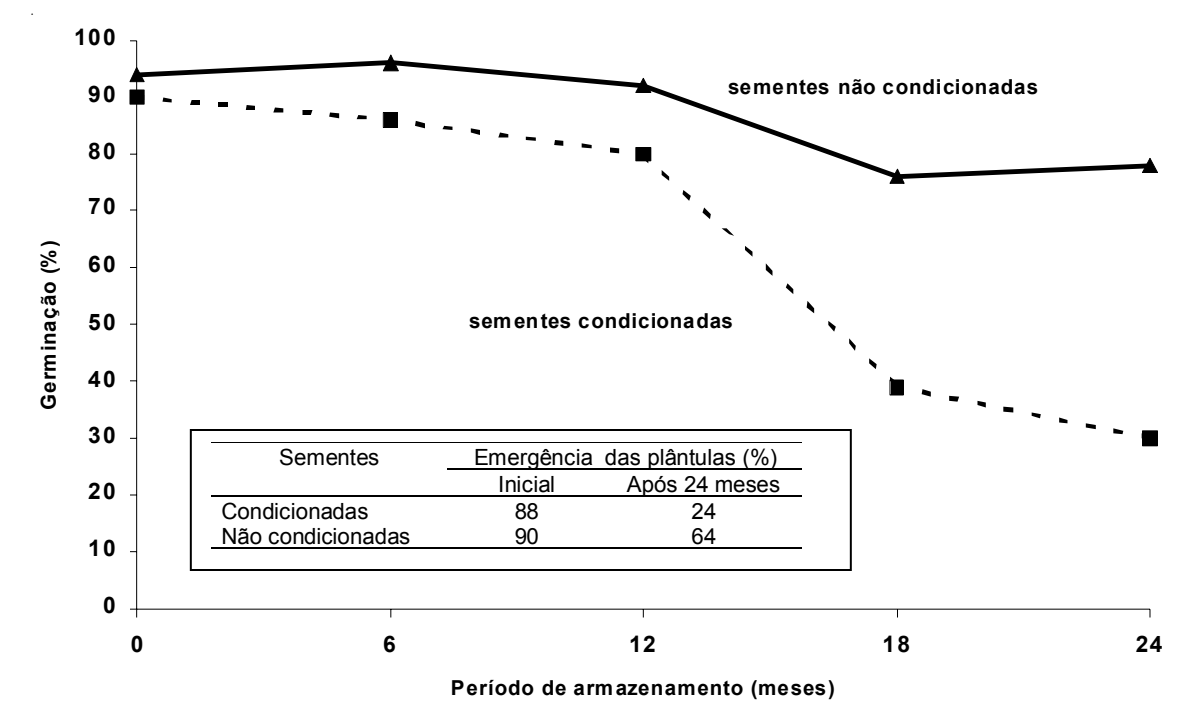

FIG. 1. Germinação de sementes de melão 'Top Net SR', a $25^{\circ} \mathrm{C}$, osmoticamente condicionadas ou não condicionadas durante 24 meses de armazenamento. 
do condicionamento osmótico seja relativamente simples, vários fatores podem influenciar seu sucesso, dentre eles, o tipo de solução osmótica, potencial osmótico, temperatura, período de embebição, aeração, luz, lavagem e secagem das sementes (Nascimento, 1998). Alguns desses fatores podem, inclusive afetar a longevidade das sementes. Por exemplo, Nascimento \& West (2000) relataram, que as condições de secagem, após o condicionamento osmótico, influenciaram o desempenho das sementes de melão, especialmente daquelas que foram armazenadas após o tratamento; neste estudo, os autores observaram decréscimos na germinação e no vigor das sementes condicionadas após 12 meses de armazenamento. Em alface, Nascimento \& Cantliffe (1998) observaram diferenças de longevidade entre genótipos e períodos de embebição durante o condicionamento osmótico das sementes. O mecanismo que leva ao aumento da deterioração das sementes após o condicionamento osmótico não é totalmente conhecido. Estudos nesse sentido devem ser enfatizados visando, simultaneamente, alcançar um efeito positivo do condicionamento e minimizar os efeitos deletérios durante o armazenamento.

\section{CONCLUSÕES}

Sementes condicionadas de melão apresentaram maior deterioração durante o período de armazenamento, comparado com as sementes não condicionadas.

\section{REFERÊNCIAS}

ALVARADO, A.D. \& BRADFORD, K.J. Priming and storage of tomato (Lycopersicon lycopersicum) seeds. I. Effects of storage temperature on germination rate and viability. Seed Science and Technology, Zürich, v.16, n.3, p.601-612, 1988.

ARGERICH, C.A.; BRADFORD, K.J. \& TARQUIS, A.M. The effects of priming and ageing on resistance to deterioration of tomato seeds. Journal of Experimental Botany, London, v.40, n.214, p.593-598, 1989.

BRADFORD, K.J. Seed priming improves germination and emergence of cantaloupe at low temperature. HortScience, Alexandria, v.20, n.3, p.598, 1985.

BRADFORD, K.J.; MAY, D.M.; HOYLE, B.J.; SHIBINSKI, Z.S.; SCOTT, S.J. \& TYLER, K.B. Seed and soil treatments to improve emergence of muskmelon from cold or crusted soils. Crop Science, Madison, v.28, n.6, p.1001-1005, 1988.

CARPENTER, W.J. \& BOUCHER, J.F. Proper environmental improves the storage of primed pansy seed. HortScience, Alexandria, v.26, n.12, p.1483-1485, 1991.
DEARMAN, J.; BROKLEHURST, P.A. \& DREW, R.L.K. Effects of osmotic priming and aging on onion seed germination. Annals of Applied Biology, Cambridge, v.108, n.3, p.639-648, 1986.

DEARMAN, J.; DREW, R.L.K. \& BROCKLEHURST, P.A. Effect of osmotic priming, rinsing and storage on the germination and emergence of carrot seed. Annals of Applied Biology, Cambridge, v.111, n.3, p.723-727, 1987.

DHILLON, N.P.S. Seed priming of male sterile muskmelon (Cucumis melo L.) for low temperature germination. Seed Science and Technology, Zürich, v.23, n.3. p.881-884, 1995.

GEORGHIOU, K.; THANOS, C.A. \& PASSAM, H.C. Osmoconditioning as a means of countering the aging of pepper seeds during storage. Annals of Botany, London, v.60, n.3, 279-285, 1987.

HARRINGTON, J.F. Seed storage and longevity. In: KOZLOWSKI, T.T. (ed.). Seed biology. New York: Academic Press, 1972. vol.3, p.145-245.

MAUDE, R.B.; DREW, R.L.K.; GRAY, D.; BUJALSKI, W. \& NIENOW, A.W. The effects of storage on the germination and seedling abnormalities of leek seeds primed and dried by different methods. Seed Science and Technology, Zürich, v.22, n.2, p.299-311, 1994.

NASCIMENTO, W.M. Condicionamento osmótico de sementes de hortaliças: potencialidades e implicações. Horticultura Brasileira, Brasília, v.16, n.2, p.106-109, 1998.

NASCIMENTO, W.M. \& CANTLIFFE, D.J. Performance of lettuce primed seeds during storage conditions. Proceedings of Florida State Horticultural Society, Tampa, v.111, p.96-99, 1998

NASCIMENTO, W.M. \& WEST, S.H. Priming and seed orientation affect seed coat adherence and seedling development of muskmelon transplants. HortScience, Alexandria, v.33, n.5, p.847-848, 1998.

NASCIMENTO, W.M. \& WEST, S.H. Muskmelon transplant production in response to seed priming. HorTechnology, Alexandria, v.9, n.1, p.53-55, 1999.

NASCIMENTO, W.M. \& WEST, S.H. Drying during muskmelon (Cucumis melo L.) seed priming and its effects on seed germination and deterioration. Seed Science and Technology, Zürich, v.8, n.1, p.211-215, 2000.

NERSON, H. \& GOVERS, A. Salt priming of muskmelon seeds for low-temperature germination. Scientia Horticulturae, Amsterdam, v.28, n.1/2, p.85-91, 1986.

ODELL, G.B. \& CANTLIFFE, D.J. Seed priming procedures and the effect of subsequent storage on the germination of fresh market tomato seeds. Proceedings of Florida State Horticultural Society, Tampa, v.99, p.303-306, 1986.

OLUOCH, M.O. \& WELBAUM, G.E. Effect of postharvest washing and post-storage priming on viability and vigour of six-yearold muskmelon (Cucumis melo L.) seeds from eight stages of development. Seed Science and Technology, Zürich, v.24, n.1, p.195-209, 1996. 
PASSAM, H.C.; KARAVITES, P.I.; PAPANDREOU, A.A.; THANOS, C.A. \& GEORGHIOU, K. Osmoconditioning of seeds in relation to growth and fruit yield of aubergine, pepper, cucumber and melon in unheated greenhouse cultivation. Scientia Horticulturae, Amsterdam, v.38, n.3/4, p.217-216, 1989.

SANFIELD, D.M.; ZAJICEK, J.M. \& COBB, B.G. Germination of Coreopsis lanceolata and Echinacea purpurea seeds following priming and storage. HortSience, Alexandria, v.25, n.12, p.1605-1606, 1990.
WELBAUM, G.E. \& BRADFORD, K.J. Water relations of seed development and germination in muskmelon (Cucumis melo L.). VI. Influence of priming on germination responses to temperature and water potential during seed development. Journal of Experimental Botany, London, v.42, n.236, p.393399, 1991.

YEOUNG, Y.R.; WILSON JR., D.O. \& MURRAY, G.A Germination performance and loss of late-embryogenesisabundant (LEA) proteins during muskmelon seed priming. Seed Science and Technology, Zürich, v.24, n.3, p.429-439, 1996. 